\title{
The Restriction of Character Discourse in Textual Context-A Case Study of Chameleon
}

\author{
Sun Ying \\ School of Foreign Studies, Weinan Normal University, Weinan, Shaanxi, 714000
}

Keywords: textual context; character discourse; Chameleon

\begin{abstract}
Chekhov, hailed as a master of short stories, has a unique perspective and taste in literary creation. Chameleon precisely depicts the dominance of the tsarist era with delicate nuanced and spicy touches. From the hero's fickle conversations, readers can catch a glimpse of flattery with bully pro-style social atmosphere at the time. This paper, based on the textual context, explores Chekhov's unique and brilliant writing skills and the restriction of characters' discourse.
\end{abstract}

\section{Introduction}

Language description is the textual contextual characteristic of Chameleon. The text concentrates on the speech and behavior of Otchumyelov, and through the dramatic and satirical discourse reversal, he succeeds in shaping the image of a beadle inscribed on the scene. In the textual context, characters discourse shows identity, character and time constraints. Through the positive description and sideways contrast, characters discourse has a strong sense of reality and authenticity, which makes the novel filled with very high social value.

\section{Linguistic Features of Chameleon}

The text begins with Otchumyelov's appearance, making him a center point of reading. First, it reveals the identity of Otchumyelov who is a police. In Tsarist times, the police were at the end of society and belong to the ruling class. Therefore, Otchumyelov appeared in such a funny image: a brand-new army coat, with a bag, with a class of men following him in the market square. Like leisurely sketching, a vivid character of police catches people's eyes. Next, in the first incident of the dog bites, the police officer finally has the opportunity to show himself, and look at him: "Body slightly to the left," "crowded into the crowd," these two actions will be arrogant and urgent for well describing the image of a police. Later, at the trial of the lawsuit, Otchumyelov was rightly justified and occasionally flattering. Even more ridiculous was his flattery in the face of a dog without its master's presence. For example, when he heard that the dog might belong to a general, he immediately changed his tone of voice and turned from "the dog must be killed" to a series of questions to Hrykin. The change in tone turned out to be timely and resourceful. When the dog was identified as not likely to belong to the general, he turned again into a caring police officer concerned with Hrykin: "You, Hrykin, have been suffering, and we won't leave you alone." The quick change is indeed a remarkable one. At this point, the image of the chameleon with greasiness represented by Otchumyelov is already alive and well described.

Chekhov's fiction is fluent in nature and vivid in conversation design. In Chameleon, dialogue of characters is the main body of the text, which shows characters through a large number of language descriptions. For example, the merchant Hrykin, who was bitten by a dog, called the crowd to catch a dog after breaking the tongue. The momentum was rather alarming. After seeing the police officer, he used a humble way to argue. Before and after the imposing manner is obviously different, such as when chasing the dog, he scolded the dog to death. When he saw Otchumyelov, he emphasized he's a good man doing his own things, and hadn't the wish to provoke the dog, and then stressed the loss of his finger injury. Hrykin showed his intention in terms of extorting money. And he also used law to fight for his interest and call for perople's support: "If everyone is bitten by a dog, its better not to be alive in this world." Rogue momentum is shown by his exaggeration. When someone 
pointed out that the dog could belong to a general, in the face of undefined power, Hrykin emphasized once again that "everyone is equal now." And he announced that his brother was in the military. When it is finally confirmed that the dog belonged to the general's brother, he had nothing to say. The dialogue is natural and fluid, the figure of Hrykin becomes a vivid one: He is the representative of the commoners. He makes every attempt to reap the benefits of non-profit, but this advantage also depends on what appears to him. If it is a small citizen like himself, he naturally pursues the truth. If it is a character with high status, he can only keep quiet. The silent irony reveals a "chameleon" characterized as freeloader, fear of power, and hypocritical.

\section{The Restriction of Character Discourse of Chameleon}

Chameleon has few characters, but focuses on shaping the arrogant and trendy police, as well as the small sophisticated and greedy citizen. Both showed strong identity features in the use of language. Otchumyelov was a police officer, a small role in the Tsarist time, but he was bound to bring a patrolman. The patrolman who gave him his word was his humble identity Portrayal. Obviously, Otchumyelov is not satisfied with humbleness, and he always puts pressure on others to elevate himself. For example, he clearly saw Hrykin chasing a dog and knew that he was bitten by the dog, but he still pummeled him with questions after pushing through the crowds. It seems that he was trying to figure out the situation, but actually he just meant to declare his identity as a police officer to the crowd, indicating "this is in charge of me, I am exercising the power of a police officer, and you all have to listen to me." However, this police officer, who is also at the bottom of society, still made his living by flattering and bullying civilians by nature, except his words and deeds. The design of language makes the law and human feelings as a contradiction, it appeared in the police officer's discourse system, suggesting that the impact of fairness and power on the identity of police officers. The Otchumyelov 's chameleon character becomes the climax of the text through the wavering between the law and human feelings. In addition, there is an important item in the text, the military coat, which appeared three times in all, it shows both the identity of Otchumyelov and his subtle occupational status.

The novel uses the chameleon's biological habits to satirize people who tends to change his view according to circumstances. In the text context of "chameleon," character traits are another aspect of the restriction of the characters' words. First of all, as the main character, Otchumyelov changes variably in the text, his behaviors are described vividly in the text. The most ridiculous thing is that when he heard that the dog belonged to the general, his attitude changed, he not only stopped shouting and screaming, but even began to praise this three-legged dog with kind words, which reveals his obsequious personality. From the perspective of textual context, the design of the discourse of Otchumyelov fully shows the personality of the character which influences the character discourse. When he just squeezed into the crowd to see this unknown dog, he said, "Give him the works!"While he knew the dog's owner, he swiftly changed his attitude: "How can the general's dog bite you", implying that the general's dog is also good. Otchumyelov's attitude changed as relationship between the dog and the general was confirmed. He wanted to beat the dog and then uttered flattery words to the dog, ordering constable to verify if it belonged to the general and emphasizing it was found by him. Finally the cook explained it didn't belong to the general but was treasured by the general's brother. The officer changed his attitude again, always adhering to flattering the general even the general's dog. Through the discourse and clue of the dog's owner, the article completely illustrates the underclass's capriciousness and obsequiousness, especially the inferior officer. The discourse is in line with the characters' personalities and changes with them.

Chameleon points out the core of profound social issues and reveals the human nature and social phenomenon using a small life scene. The three-legged dog is undoubtedly an important clue to this story. In the context of text, the origins of dog became discourse factors that reflected the social system and characteristics of the regime at that time. The dog's ownership and the owner's social status determine the attitude of the police officers and the civilians, which are the primary factors in the change of characters' discourse. When the owner may be a civilian, the officer Otchumyelov decided to beat and kill the dog. While the dog's owner may be a general, the police officer would 
be extremely sycophantic and sucked up to a dog. Such a seemingly absurd scene is actually a typical abbreviation of Russian society in the Tsarist era. Before and after 1880, during the darkest period of Russian rule, handicraftsmen and civilians went bankrupt, and the military and political classes were the spokespersons of the tsarist pressure regime. Therefore, Even if the generals did not show up, it would be all right for the dog to bite if he was in his family, and it was also extremely honorable. On the one hand, the small bureaucrats and villagers in the grassroots society, such as Otchumyelov and Hrykin, faces the power insensitivity, on the other hand reveals humbleness and servility from the bones, addicted to obedience to welcome the power and honor, at the expense of human dignity and principles. In this paper, the use of positive dialogue description, as well as action, demeanor side of the setting, the atmosphere to create and other practices, the depiction of the characters in depth, character discourse by the times, with a strong discourse characteristics of the times.

\section{Conclusions}

Drawing on the social life, the Chameleon succeeded in shaping the image of the minor under the social tyranny, showing the criticism of the irrational social system and the unscrupulous whipping about the citizen class. Textual constraints in human speech not only express satirical and critical words in a vivid and natural language and create a vivid artistic image, but also make in-depth understanding of the causes of characters and characteristics of the times and the social background of characters. Then the theme of the text is rich and vivid, becoming an immortal literary classic.

\section{References}

[1] Yu Qiutan. The Creation Style and Character Language Features of 'Chameleon' [J]. Chinese Construction, 2014(29):41-42.

[2] Wang Ming. Interpretation of 'Chameleon' from the Break of Character Words [J]. Middle School Chinese Teaching Reference, 2017(26):63-64. 